\title{
Proinflammatory cytokine and cytokine receptor gene expression kinetics following challenge with Flavobacterium psychrophilum in resistant and susceptible lines of rainbow trout (Oncorhynchus mykiss).
}

Ivan Kutyrev ${ }^{1,2, *}$, Beth Cleveland ${ }^{1}$, Timothy Leeds ${ }^{1}$, and Gregory D. Wiens ${ }^{1 *}$

${ }^{1}$ National Center for Cool and Cold Water Aquaculture, Agricultural Research Service, USDA, 11861 Leetown Rd,

Kearneysville, WV 25430, USA

${ }^{2}$ Institute of General and Experimental Biology, Siberian Branch of Russian Academy of Sciences, Sakhyanovoi St., 6, 670047 Ulan-Ude, Russia

*Corresponding Author(s): email greg.wiens@ars.usda.gov and ivan.kutyrev@yahoo.com.

Abbreviations: BCWD, bacterial cold water disease; Fp, Flavobacterium psychrophilum; NCCCWA, National Center for Cool and Cold Water Aquaculture; GeXP, GenomeLab Gene Expression Profiler genetic analysis system; TNF, tumor necrosis factor; LOD, limit of detection; CFU, colony forming unit; i.p., intraperitoneal; A.U., arbitrary density units; GE, genome equivalent. 


\begin{abstract}
Flavobacterium psychrophilum $(F p)$ is the causative agent of bacterial cold water disease (BCWD) which causes appreciable economic losses in rainbow trout aquaculture. We previously reported development of a genetic line, designated ARS-Fp-R that exhibits higher survival relative to a susceptible line, designated ARS-Fp-S, following either laboratory or natural onfarm challenge. The objectives of this study were to determine the temporal kinetics of gene expression between experimentally-challenged ARS-Fp-R and ARS-Fp-S fish and the correlation between gene expression and pathogen load. We developed a GeXP multiplex RTPCR assay to simultaneously examine expression of immune-relevant genes, concentrating on tumor necrosis factor and interleukin-1 ligand/receptor systems and acute phase response genes. Spleen tissue was sampled at 6h, 24h, 48h and 144h post-challenge and pathogen load quantified by qPCR. Transcript abundance of cytokine genes tnfa1, tnfa2, tnfa3, illb1, illb2, ill1a; acute phase response genes saa and drtpl; and putative cytokine receptors illrl-like-b, illr2, tnfrsfla, tnfrsf9, tnfrsfla-like- $b$ increased following challenge while the transcript abundance of illr-like-1 and tnfrsfla-like-a decreased compared to PBS-injected line-matched control fish. Principal component analysis identified transcript levels of genes illr-like-1 and tnfrsfla-like-a as exhibiting differential expression between genetic lines. In summary, $F p$ i.p. injection challenge elicited a proinflammatory cytokine gene expression response in the spleen, with ARS-Fp-R line fish exhibiting modestly higher basal expression levels of several putative cytokine receptors. This study furthers the understanding of the immune response following $F p$ challenge and differences in gene expression associated with selective breeding for disease resistance.
\end{abstract}

Keywords: Flavobacterium psychrophilum, bacterial cold water disease, genetic resistance, selective breeding, proinflammatory cytokines, and cytokine receptors. 


\section{Introduction}

Genetic improvement programs contribute to increased aquaculture productivity and animal welfare through selection and generation of animals with improved resistance/tolerance against infectious disease-causing microorganisms [1-5]. In 2005, a family-based selective breeding program was initiated at the National Center for Cool and Cold Water Aquaculture (NCCCWA) to improve rainbow trout (Oncorhynchus mykiss) survival following exposure to the gramnegative bacterium, Flavobacterium psychrophilum [6]. This pathogen is the etiologic agent of bacterial cold water disease (BCWD) and rainbow trout fry syndrome that causes considerable losses to the U.S. rainbow trout aquaculture industry and to trout and salmon populations worldwide $[7,8]$. Infection of rainbow trout with $F$. psychrophilum typically results in mortality, ranging from 2 to $30 \%$ of the population, with higher losses caused by coinfection with the infectious hematopoietic necrosis virus. Disease prevention is difficult as the pathogen is geographically widespread, fish are often affected at early life-stage, and limited chemotherapeutants are available for treatment. There is currently no commercial vaccine available in the U.S, although killed, subunit, and live-attenuated vaccines are actively being evaluated, and several vaccines have demonstrated protection under laboratory and field conditions $[9,10]$.

A pedigreed line of rainbow trout, designated ARS-Fp-R, has been subjected to five generations of family-based selection and demonstrates increased survival following experimental injection challenge $[6,11,12]$ and natural exposure $[13,14]$, compared to a disease-susceptible line designated ARS-Fp-S. Current research goals at the NCCCWA include elucidating the intrinsic factors associated with the ARS-Fp-R line to understand the mechanism(s) of how selection has altered the genetic control of survival post-challenge. Measurement of gene expression differences between fish families, or genetic lines, has 
contributed to the understanding of the genetic basis of immunological responsiveness [15-25]. Previously, we reported analysis of whole-body gene expression, using RNA-Seq, to quantify changes in gene transcript abundance between genetic lines [26] and identified 1884 genes (4.0\% of the protein coding transcripts identified in the rainbow trout genome) that exhibited differential transcript expression between infected and mock-challenged fish (FDR $<0.05)$. Regulated genes included interleukins, tumor necrosis factor (TNF) receptor superfamily members, chemokines, complement components, nod-like receptor family members, and genes putatively involved in metabolism and wound healing. ARS-Fp-S line fish exhibited a greater number of regulated genes with expression levels that correlated to $F p$ load measured at day 5 post-infection. A limitation of this study was that samples were pooled by genetic-line thereby obscuring inter-individual variation and the direct correlation of gene expression with pathogen load. Also, RNA was extracted from the whole-body of small fish (avg. bwt. $1.1 \mathrm{~g}$ ) and thus lowabundance and organ-specific transcripts were possibly underrepresented or absent within the dataset.

Following gram-negative, bacterial pathogen exposure, mammals and teleost fish produce proinflammatory cytokines and an acute phase response leading to cellular activation and elicitation of effector pathways involved in bacterial killing, clearance, tissue resolution and healing [27-29]. TNF and interleukin-1 (IL-1), as well as several related family members, are important mediators of the mammalian initial proinflammatory response. Inhibition of human TNF or IL1 $\beta$ bioactivity is able to counteract mortality associated with endotoxin-induced shock $[30,31]$. Thus, appropriate regulation of these cytokines and their cognate receptors can be critical for survival. At present, it is unclear whether transcriptional regulation of 
proinflammatory cytokines, and associated receptors, contribute to the survival difference between the ARS-Fp-R and ARS-Fp-S genetic lines in response to Fp challenge.

Measurement of paralogue specific gene-expression in salmonid fish is challenging due to the putative whole-genome duplications occurring in the basal teleost lineage and the salmonidspecific lineage [32,33], as well as subsequent, local duplication(s) [34]. Multiple paralogs with complex evolutionary history are often present that are closely related in sequence. The availability of the recently published rainbow trout genome sequence [32] has facilitated initial efforts toward a comprehensive tabulation of immune-related genes [26]. In this manuscript, we investigate proinflammatory cytokine gene expression focusing on rainbow trout paralogues of tnf and $i l 1$ and putative cognate receptors. In order to simultaneously investigate expression changes in this suite of genes, we developed a multiplex GeXP assay [35] that measures multiple rainbow trout cytokines and putative receptor transcripts in a single reaction. A similar system has been recently used to dissect cytokine responsiveness in Takifugu [36]. The rainbow trout assay also includes genes encoding acute phase proteins, serum amyloid a (saa) and differentially regulated protein $1(d r t p l)$, as well as interleukin-11 (ill la). These genes were previously identified as upregulated in whole-body lysates following $F p$ challenge [26] and ill $1 a$ is known to be upregulated in the rainbow trout spleen following bacterial challenge [37]. Herein, we analyze the expression kinetics of a suite of immune genes in spleen tissue of juvenile (avg. bwt. 270g) rainbow trout following i.p. injection of $F p$. The correlation between gene expression and pathogen load was determined as well as differential basal and induced responses between the two genetic lines. 


\section{Material and Methods}

\subsection{Experimental animals: Generation of rainbow trout ARS-Fp-R and ARS-Fp-S genetic lines.}

Fish were maintained at the National Center for Cool and Cold Water Aquaculture (NCCCWA) and animal procedures were performed under the guidelines of NCCCWA Institutional Animal Care and Use Committee Protocol \#096. Briefly, ARS-Fp-R and ARS-Fp-S genetic lines were derived from the same base population, and thus differed only as a result of artificial selection for BCWD post-challenge survival [38]. All fish utilized in this study were from the 2014 year class. Single-sire $\times$ single-dam matings were made within genetic lines between 3-year-old females and 1-year-old neomales as previously described [39]. Water temperatures in the egg incubation jars were manipulated so that all families hatched within a one-week period [12]. Eggs were pooled within-line at the eyed stage and reared in $\sim 12.5{ }^{\circ} \mathrm{C}$ flow-through spring water. The ARS-Fp-R egg pool consisted of contributions from 90 full-sib families and the ARS-Fp-S egg pool consisted of 7 full-sib families. Eggs were pooled from a larger number of resistant-line families as more families were generated within the breeding program to supply a large-scale farm trial, and thus this sampling design more accurately captured the genetic diversity within the resistant-line. The resistant-line eggs were progeny of dams that had undergone four generations of BCWD selection while the sires had undergone five generations of selection. The susceptible-line eggs were progeny of parents that had undergone one generation of selection for increased susceptibility (2007 year-class) and, thereafter randomly bred to maintain genetic diversity and minimize inbreeding accumulation [38].

\subsection{Sampling}

Prior to challenge, fish ( $n=22$ per tank) were allowed 2 weeks to acclimate to challenge tanks (45 L). Replicate tanks were used for each treatment (genetic line, $F p$ challenge; $\mathrm{n}=8$ tanks total). 
Photoperiod was adjusted weekly in the challenge facility to maintain a natural lighting cycle, and at the time of tissue collection was $13 \mathrm{~h}$ light and $11 \mathrm{~h}$ dark. Water quality parameters at the NCCCWA have been described previously [38]. Fish were challenged by intraperitoneal injection with $500 \mu \mathrm{L}$ of PBS alone, or PBS containing $2.3 \pm 0.4 \times 10^{8} \mathrm{CFU}$ of the genomesequenced strain of F. psychrophilum CSF259-93 [40]. During the experimental challenge period, one ARS-Fp-S line fish died on day 4 and $F p$ was confirmed by plate culture using TYES media.

At $6 \mathrm{~h}, 24 \mathrm{~h}, 48 \mathrm{~h}$ and $144 \mathrm{~h}$ post-injection, fish were sampled at random ( $\mathrm{n}=5$ per tank) and euthanized using $200 \mathrm{mg} / \mathrm{L}$ tricainemethanesulfonate (tricane-S; Western Chemical, Inc., Ferndale, WA, USA). Fish were then weighed and a blood sample collected in a lithium vacutainer through the caudal vasculature as described [41]. Body weight of ARS-Fp-R line fish averaged $265 \pm 70 \mathrm{~g}$, and the ARS-Fp-S line averaged $271 \pm 52 \mathrm{~g}( \pm 1 \mathrm{SD})$. Following blood plasma collection, the tail was removed to drain excess circulatory blood. Dulbecco's PBS was added to suspend and capture peritoneal cavity cells, and once completed, the spleen removed and weighed. Spleen weight was normalized to total body weight to calculate spleen-index (SI) as described previously [11]. Two spleen tissue samples (10 and $100 \mathrm{mg}$ ) and a kidney tissue sample $(100 \mathrm{mg})$ were dissected, placed in labeled tubes and frozen in liquid nitrogen. Peritoneal cavity cells were pelleted for $10 \mathrm{~min}$ at $500 \mathrm{x} \mathrm{g}$ at $4^{\circ} \mathrm{C}$ and flash frozen. Sample storage tubes were transferred from liquid nitrogen to storage at $-80{ }^{\circ} \mathrm{C}$. Each $100-\mathrm{mg}$ spleen sample was subjected to RNA extraction, and each 10-mg spleen sample to DNA extraction for quantification of $F p$ genomic DNA.

\section{3. qPCR detection of F. psychrophilum load in the spleen.}


DNA was extracted from $10 \mathrm{mg}$ spleen tissue using the DNeasy Blood \& Tissue Kit (Qiagen) with a final elution in $200 \mu \mathrm{L} 10 \mathrm{mM}$ Tris/ $1 \mathrm{mM}$ EDTA, and the purified DNA was quantified using a Nanodrop ND-1000 spectrophotometer (Thermo Scientific). Polymerase chain reaction was performed using hydrolysis probes (TaqMan ${ }^{\circledR}$, Applied Biosystems) targeting a conserved single-copy, sequence in the F. psychrophilum genome as previously described [42]. Reaction mixtures consisted of 7.5 $\mu$ L TaqMan Universal Master Mix II+UNG (Life Technologies), 0.67 $\mu \mathrm{M}$ forward and reverse primers, $0.17 \mu \mathrm{M}$ probe, $1.5 \mu \mathrm{L}$ (standard curve) or $4.5 \mu \mathrm{L}$ (samples), and nuclease-free water added to a total volume of $15 \mu \mathrm{L}$. Samples were run in duplicate with water used as a no-template control. An ABI 7900HT real-time thermal cycler (Applied Biosystems) was used to amplify the target sequence using absolute quantification with the machine's default program of initial denaturation for $15 \mathrm{~min}$ at $95^{\circ} \mathrm{C}$ and 40 cycles of 15 seconds at $95^{\circ} \mathrm{C}$ and 1 minute at $60^{\circ} \mathrm{C}$. Results were normalized to $F$. psychrophilum genome equivalents (GE) per $100 \mathrm{ng}$ of sample DNA to account for variation in tissue quantity and DNA extraction efficiency [42]. Of the $80 \mathrm{Fp}$ challenged fish, a total of 9 ARS-Fp-R line fish ( $\mathrm{n}=4$ from $24 \mathrm{~h}$, $\mathrm{n}=2$ from $48 \mathrm{~h}, \mathrm{n}=3$ from $144 \mathrm{~h}$ sampling time point) and 1 ARS-Fp-S line (144h) fish had qPCR cycle threshold $(\mathrm{Ct})$ values below detection (assay sensitivity of 3 GE per reaction with an average limit of detection (LOD) $=0.19 \mathrm{GE} 100 \mathrm{ng}^{-1}$ for all samples). The ten infected, qPCRnegative fish were conservatively assumed to have not completely cleared the pathogen and thus $F p$ loads were estimated based on the LOD divided by the square root of 2 as described [43] using the formula:

Estimated GE $100 \mathrm{ng}^{-1}=((3 \mathrm{GE}$ sample*100)/(ng DNA tested in the reaction) $) / \mathrm{sqrt} 2$. Since these samples were primarily from the ARS-Fp-R line fish, the estimates may have reduced the actual $F p$ load difference between the two lines. A total of 20 PBS-injected fish 
were chosen from the $48 \mathrm{~h}$ and $144 \mathrm{~h}$ sampling time points and these were below the level of

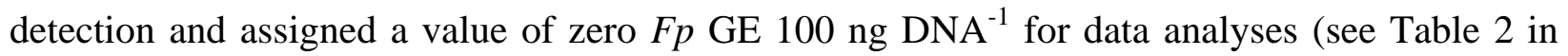
[44].

\subsection{RNA isolation.}

To isolate RNA, 75-100 mg of spleen tissue was homogenized in 1mL TRIzol (Invitrogen; Carlsbad, CA, USA), using a 5-mm steel bead and a multi-tube shaker, followed by phenol extraction per the manufacturer's protocol. The RNA pellet was washed twice with $75 \%$ ethanol, dried, and suspended in nuclease-free water. RNA concentration and purity were determined by measuring absorbance, and the A260/A280 ratio varied between 1.99 and 2.08. RNA quality was evaluated by agarose gel electrophoresis.

\subsection{Gene expression analysis}

We utilized the GenomeLab Gene Expression Profiler (GeXP) genetic analysis system (Beckman Coulter Inc.; Pasadena, CA, USA) to quantify transcript abundance using reverse transcription (RT)-PCR. In this system, capillary electrophoresis was used to separate and quantify the size and fluorescence intensity of the amplicons produced by a single endpoint PCR reaction. Primers were either derived from previously published studies [45-48] or designed de novo using eXpress Designer software (Beckman Counter Inc.; Pasadena, CA, USA) to produce amplicons between 100 - 400 base pairs, each separated by a minimum of three bases (Table 1). Within the multiplex, 21 primer pair's amplified genes associated with the fish immunological response and four served as reference genes (Table S1). Primer sequences were compared against other rainbow trout gene sequences using the BLAST function within the NCBI database 
to reduce unintended sequence amplification. The pair of primers designed to amplify the gene(s) annotated as illr-like-1 did not discriminate between gene paralogues (GSONMT00035358001, GSONMT00021943001, and GSONMT00035357001) (Table 1). Subsequent analysis of an improved assembly of the rainbow trout genome (Palti et al. unpublished data) uncovered that several primer sets amplify multiple paralogues of saa, drtpl, ill1a, illr-like-1 and the housekeeping genes (Table S1). For convenience, we refer to each primer pair as amplifying a gene(s) having a common annotation. Optimization of the multiplex, standard curve dilutions (3 - 50 ng per reaction), RT and PCR reactions, and capillary electrophoresis were performed as recommended by the manufacturer (GeXP Chemistry protocol A29143AC; February, 2009) with reagents provided in the GeXP Start Kit (Beckman Coulter Inc.; Pasadena, CA, USA). The size of each amplicon was confirmed with its expected length with the exception of the illb4 gene transcript which was not detected. Representative amplification profiles are presented (see Figure 1 in [44]). GeXP gene expression values for illla and tnfrsf5 were significantly correlated with gene expression values measured by conventional RT-PCR, albeit the GeXP assay for ill la was less sensitive in measuring low amounts of gene expression (see Figure 2 in [44]). Gene names, gene symbols, GenBank accession numbers, and database reference numbers are listed (Table 1). Primer sequences that include universal tags, genomic location and standard curve efficiencies are provided in a supplementary data file (Table S1).

Reverse transcription reactions included 100 ng of DNase (Promega, Madison, WI) treated RNA in $1 \mu \mathrm{L}, 2 \mu \mathrm{L} 5 \mathrm{X}$ RT buffer, $1 \mu \mathrm{L}$ gene-specific reverse primer mix, $0.5 \mu \mathrm{L}$ RT enzyme, and $1.25 \mu \mathrm{L}$ kanamycin RNA (internal control) in a $10 \mu \mathrm{L}$ reaction. The RT was incubated according to kit instructions at $48{ }^{\circ} \mathrm{C}$ for $1 \mathrm{~min}, 42{ }^{\circ} \mathrm{C}$ for $60 \mathrm{~min}$, then $95{ }^{\circ} \mathrm{C}$ for $4 \mathrm{~min}$. An aliquot $(4.65 \mu \mathrm{L})$ of the resultant cDNA was used in a PCR reaction with $2 \mu \mathrm{L} 25 \mathrm{mM} \mathrm{MgCl}, 2$ 
$\mu \mathrm{L} 5 \mathrm{X}$ PCR buffer, $1 \mu \mathrm{L}$ forward primer mix, and $0.35 \mu \mathrm{L}$ DNA Taq polymerase. The PCR was incubated according to kit instructions at $95^{\circ} \mathrm{C}$ for $10 \mathrm{~min}$ then 34 cycles of $94{ }^{\circ} \mathrm{C}$ for $30 \mathrm{sec}, 55$ ${ }^{\circ} \mathrm{C}$ for $30 \mathrm{sec}$, and $70{ }^{\circ} \mathrm{C}$ for $60 \mathrm{sec}$. One $\mu \mathrm{L}$ of PCR products was combined with $38.5 \mu \mathrm{L}$ sample loading solution and $0.25 \mu \mathrm{L}$ size standard 400 . The PCR products were separated by capillary electrophoresis in the GeXP Genetic Analysis System using the Frag-3 protocol with a separation voltage of $6.0 \mathrm{kV}$ for $45 \mathrm{~min}$.

The amount of fluorescence associated with each amplicon was exported to eXpress Profiler software (Beckman Coulter, Inc.; Pasadena, CA, USA) for analysis and normalization to the internal kanamycin control. The amount of fluorescence was quantified using a pooled sample, standard curve ( $\mathrm{n}=3$ technical replicates, comprising 8 dilutions of cDNA). For each gene, the transcript concentration was measured in arbitrary density units (A.U.). Standard curve $\mathrm{R}^{2}$ values were between 0.81-0.97 (Table S1) with the exception of tnfrsflb which was not reliably quantified and thus excluded from further analysis. The three most stable reference genes were identified by GeNorm software as arp, gapdh, and efl $\alpha$, with M-values of $0.810,0.697$, and 0.620. Data from $a c t b$ were not used. GeNorm software calculated the geometric mean of the reference genes and generated a normalization factor for each sample. Transcript abundance for all genes was normalized to the reference genes by dividing transcript concentrations by the normalization factor. One $F p$-injected, ARS-Fp-R line fish (fish \#65, 24h) failed to produce measureable PCR products and this fish was excluded from gene expression analyses.

\subsection{Statistical analysis}

Gene expression and $F p$ load data were increased by a value of 1 and then $\log _{2}$ transformed. Fp load data were analyzed using a two-way ANOVA to identify significant differences in 
bacterial loads between genetic lines and between sample time points using GraphPad Prism version 6.0 (GraphPad Software, Inc.). Separate two-way ANOVA were likewise used to evaluate the effects of 1) genetic line (within treatment), time of sampling, and their interaction, and 2) treatment (within genetic line), time of sampling, and their interaction, on gene expression. The null hypothesis (no difference between groups) was rejected if $P<0.05$. Principal component analysis (PCA) and heat maps were generated using Qlucore Omics Explorer (v3.1). Initial data inspection identified three PBS-injected fish from tank 4 (24h) that had elevated proinflammatory gene expression profiles and gene expression values from these fish were subsequently eliminated from further analyses (Fish \#51, \#53 and \#55, see Table 2 in [44]). In addition, two fish with unusually large spleen index values were excluded from spleen size analyses (Fish \#130 and \#133, see Table 2 in [44]). For heat map generation of each variable, all data were normalized to a mean $=1$ and variance $=1$ (yellow color high, blue color low relative expression). To identify infection-regulated genes, a two-group comparison of infected vs PBS-injected fish was filtered using a false discovery rate of $q<0.05$ and a foldchange $>2.0(P=0.006)$. Using these filters, PCA component 1 accounted for $50 \%$ of the variation (Figure S2). To identify genes differentially regulated between genetic lines, a twogroup comparison of ARS-Fp-R line vs ARS-Fp-S line was filtered using a false discovery rate of $q<0.05$ and a fold-change $>2.0(P=0.002)$. Using these filters, PCA component 1 accounted for $40 \%$ of the variation. Coordinated gene expression was identified by hierarchal clustering of gene-expression values. Pearson correlation $(r)$ was used to evaluate the pair-wise relationships between log-transformed gene expression, bacterial load and spleen size. Correlations were determined using GraphPad Prism (v6.0) and considered significant if $P<0.05$. 


\section{Results}

3.1. Kinetics of Fp load change in ARS-Fp-R and ARS-Fp-S line spleen tissue following challenge.

The $F p$ GE in spleen tissue was affected by genetic line $(P=0.015)$ and time $(P=0.018)$ with no interaction between line and time $(P=0.125)$. Pairwise analyses identified significantly higher Fp loads in ARS-Fp-S line fish spleens at 48h post-infection (Figure 1). Following challenge, spleen-index significantly increased in both lines at $144 \mathrm{~h}$, with a mean increase of 0.508 SI units in the ARS-Fp-R line $(P<0.0001)$ and 0.364 units in the ARS-Fp-S line $(P=.003)$ relative to the respective PBS-injected controls (Figure S1A). Body weight was not different between PBSinjected or $F p$-injected fish or between genetic lines ( $P=0.573$, Figure S1B). These data indicate that the pathogen load difference between lines and spleen size increase following challenge was consistent with previous observations $[11,13]$.

\subsection{Principal component analysis of changes in gene expression influenced by infection.}

Principle component analysis of global gene expression using the dataset of 156 fish identified fifteen immune-relevant genes that were differentially regulated in response to $F p$ challenge. These included the cytokines tnfal, tnfa2, tnfa3, illb1, illb2, ill1a, the putative receptors tnfrsf1a, tnfrsfla-like-a, tnfrsfla-like-b, tnfrsf9, illr-like-1, illr1-like-b, illr2, as well as acute phase response genes $s a a$ and $d r t p$ (Qlucore Omics Explorer, two-group comparison of PBS-injected vs infected fish, false discovery rate of $q<0.05$ and a fold-change $>2.0, P=0.006$ ) Hierarchal clustering identified five general patterns of expression (Figure 2). Group I genes were up-regulated at the $6 \mathrm{~h}$ time point, remained elevated at $24 \mathrm{~h}$ and $48 \mathrm{~h}$ and exhibited decreased expression at 144h. This group included tnfa3, illb1, tnfal, tnfrsf9, ill1a, illr2 and 
illrl-like- $b$. Group II genes were modestly elevated at $6 \mathrm{~h}$ and by $24 \mathrm{~h}$ through $144 \mathrm{~h}$ exhibited robust upregulation and included acute phase response genes saa and $d r t p$. Group III genes, thfa2 and $i l 1 b 2$, were upregulated at $6 \mathrm{~h}$ but with diminished relative expression at $24 \mathrm{~h}$ and $48 \mathrm{~h}$ timepoints. Group IV genes, tnfrsfla-like- $b$ and tnfrsfla were not changed at $6 \mathrm{~h}$ but upregulated at 24h in ARS-Fp-S line fish. Group V genes tnfrsfla-like-a, and illr-like-1(ex3-5), were unchanged at $6 \mathrm{~h}$ and down-regulated at $48 \mathrm{~h}$ post-challenge.

\subsection{Pairwise-analysis of gene expression in response to Fp infection.}

To more precisely characterize gene expression kinetics of the thirteen infection up-regulated genes (Groups I-IV), we analyzed each gene using two-way ANOVA followed by pair-wise comparison between PBS and $F p$-injected fish by genetic line (Figure 3 A-X). Transcript abundance of saa was significantly elevated in infected fish at all time points in both lines (Figure $3 \mathrm{~A}, \mathrm{~B}$ ), and drtpl that was significantly increased in infected fish at $48 \mathrm{~h}$ and $144 \mathrm{~h}$ in the ARS-Fp-R line and 24h, 48h and 144h in the ARS-Fp-S line (Figure 3 C, D). Saa expression was significantly correlated with $d r t p l$ expression $(r=0.81)$, and the expression of both genes significantly correlated with pathogen load (saa $r=0.49$; drtpl $r=0.42$; Table S3). Two-way ANOVA identified a significant effect of genetic line for saa and $d r t p l$ with higher transcript abundance in $F p$ challenged ARS-Fp-S line compared to challenged ARS-Fp-R line fish (Table S2, 2-way ANOVA; saa, $P=0.0086 ; d r t p 1, P=0.0104)$. At the 24 h time point, saa expression was significantly higher in the $F p$ challenged ARS-Fp-S line than ARS-Fp-R line (Table S2).

Transcript abundance of genes illr2, illrl-like-b, and tnfrsf9 were significantly elevated by infection in both lines (Table S2, 2-way ANOVA, illr2, $P<0.0001$; illr1-like-b, $P<0.0001$; tnfrsf9, $P<0.0001$ ). The receptor genes were upregulated early (6h) in both lines, illr2 (Figure 3 
E, F), illrl-like-b (Figure $3 \mathrm{G}, \mathrm{H}$ ), and tnfrsf9 (Figure $3 \mathrm{I}, \mathrm{J}$ ). Illr2 transcript abundance was significantly increased at $6 \mathrm{~h}$ and $48 \mathrm{~h}$ in the ARS-Fp-R line and at all time-points in the ARS-FpS line. Illrl-like- $b$ was significantly increased at $6 \mathrm{~h}$ and $48 \mathrm{~h}$ in ARS-Fp-R line and $6 \mathrm{~h}, 24 \mathrm{~h}$ and 48h in the ARS-Fp-S line. Tnfrsf9 transcript abundance was significantly increased at $6 \mathrm{~h}$ and $48 \mathrm{~h}$ in the ARS-Fp-R line and at 6h, 24h and 48h in the ARS-Fp-S line (Figure $3 \mathrm{I}, \mathrm{J}$ ). Expression of ill $r 2$ was significantly correlated with illr1-like-b $(r=0.92)$ and tnfrsf9 $(r=0.80)$ (Table S3). Expression of $i l 1 r 1-l i k e-b$ was significantly correlated with $\operatorname{tnfrsf9}(r=0.73)$. Two-way ANOVA identified a significant effect of genetic line on expression of genes illr2, illrl-like-b, and tnfrsf 9 with higher transcript abundance in challenged ARS-Fp-S line compared to challenged ARS-Fp$\mathrm{R}$ line fish (Table S2, 2-way ANOVA, illr2, $P=0.0158$; illr1-like- $b, P=0.0416$; tnfrsf9, $P=0.0101)$.

Proinflammatory cytokine genes, tnfal, tnfa2, tnfa3, illb1, and $i l 1 b 2$ generally exhibited early (6h) up-regulation. Tnfal was significantly increased at $6 \mathrm{~h}$ and $48 \mathrm{~h}$ in ARS-Fp-R and $-\mathrm{S}$ lines (Figure $3 \mathrm{~K}, \mathrm{~L}$ ). Tnfa 2 was significantly increased at only $6 \mathrm{~h}$ in the ARS-Fp-S line (Figure $3 \mathrm{M}, \mathrm{N}$ ); and tnfa3 was significantly increased at $6 \mathrm{~h}$ and $48 \mathrm{~h}$ in the ARS-Fp-R line and at $6 \mathrm{~h}$, 24h, 48h in ARS-Fp-S line (Figure $3 \mathrm{O}, \mathrm{P}$ ). Transcript abundance of illbl was significantly increased at $6 \mathrm{~h}$ and $48 \mathrm{~h}$ in the ARS-Fp-R line and 6h, 24h, 48h in the ARS-Fp-S line (Figure 3 Q, R). Illb2 was significantly increased at $6 \mathrm{~h}$ and $48 \mathrm{~h}$ in the ARS-Fp-R line and $6 \mathrm{~h}$ and $24 \mathrm{~h}$ in ARS-Fp-S line (Figure $3 \mathrm{~S}, \mathrm{~T}$ ). Tnfa1, tnfa2 and tnfa3 gene expression were highly correlated ( $r=0.63$ to 0.80$)$ and significantly correlated with $i l 1 b 1$ and $i l 1 b 2$ ( $r=0.55$ to 0.89$)$ (Table S3). These five genes were all significantly correlated with $F p$ load ( $r=0.34$ to 0.63 ). There was no correlation between these five genes and illb3 transcript abundance. Two-way ANOVA 
identified a significant effect of genetic line only for $i l 1 b 1$ with higher expression in ARS-Fp-S line fish compared to challenged ARS-Fp-R line fish (Table S2, 2-way ANOVA, line $P=0.0147$ ).

Up-regulation of ill1a gene occurred at $6 \mathrm{~h}$ and $48 \mathrm{~h}$ in ARS-Fp-R line fish and at $6 \mathrm{~h}, 24 \mathrm{~h}$, and 48h in ARS-Fp-S line fish (Table S3). Two-way ANOVA identified a significant effect of genetic line with higher expression in challenged ARS-Fp-S line fish compared to challenged ARS-Fp-R line fish (Table S2, 2-way ANOVA, line $P=0.0033$ ). Illla gene expression was significantly correlated with other Group I genes, with the highest correlations with illb1 $(r=0.77)$ and $\operatorname{tnfa} 3(r=0.75)$.

Up-regulation of receptors tnfrsfla (Figure $3 \mathrm{U}, \mathrm{V}$ ) and tnfrsfla-like-b (Figure $3 \mathrm{~W}, \mathrm{X}$ ) were observed only in the ARS-Fp-S line at the $24 \mathrm{~h}$ time-point and the expression of these genes were highly correlated ( $r=0.85)$ (Table S3).

Tnfrsf5 ( $c d 40$ ) was not regulated in response to challenge nor did expression differ between genetic lines (Table S2).

\subsection{Comparison of the response to Fp-infection between genetic lines}

Two genes exhibited a general pattern of down-regulation in response to infection: tnfrsflalike-a, and illr-like-1 (Figure 2). The two primer sets targeting different regions of illr-like-1, either exons 3-5 or 9-11, identified a similar trend of downregulation but not identical values at time points (Figure 2, Table S2). Interestingly, when the dataset was filtered by principle component analysis for genes that significantly differed between genetic lines, both tnfrsfla-like$a$ and illr-like-1 genes were identified (including both $F p$-infected and PBS-treated fish in the analyses) (Figure 4). Within this global analysis, spleen weight and spleen index also significantly differed between genetic lines (Figure 4) even after accounting for infection and 
time. The ARS-Fp-R line fish tended to exhibit larger relative spleen size and higher expression of genes tnfrsfla-like-a, and illr-like-1. Gene expression of tnfrsfla-like-a was significantly correlated with both illr-like-1(ex3-5) $(r=0.49)$ and illr-like-1(ex9-11)( $r=0.32)$. Tnfrsfla-like-a, and illr-like- 1 were negatively correlated with $F p$ load $(r=-0.32,-0.42$ (ex3-5) and -0.20 (ex911) respectively). However, neither of these genes were significantly correlated with spleen weight or spleen index values suggesting that these are independent characteristics exhibited by the genetic lines in response to $F p$ challenge (Table S3).

\subsection{Comparison of baseline and induced gene expression between genetic lines.}

We next explored whether the differences between genetic lines were the result of baseline or induced differences. When the entire data set of PBS-injected animals was analyzed by pair-wise comparison, tnfrsfla-like-a, illr-like-1(ex3-5) and illr-like-1(ex9-11) were all significantly higher in the ARS-Fp-R line compared to the ARS-Fp-S (Figure 5 A, B and C). When analyzed by time-point, significant differences in gene expression between PBS-injected ARS-Fp-R and ARS-Fp-S line fish were identified only at $6 \mathrm{~h}$ post-injection for illr-like-1 (ex3-5 and ex9-11) (Table S2). Thus, subtle differences in gene expression were detected in PBS-injected fish. Comparison of the $F p$-injected ARS-Fp-R and ARS-Fp-S line fish identified modest, but significantly higher relative expression (absence of down-regulation) in the ARS-Fp-R line compared with ARS-Fp-S line (Figure 5 D-F). We next examined if expression also differed between lines of infected animals. Gene expression of tnfrsfla-like-a and illr-like-1(ex9-11) were significantly higher at $48 \mathrm{~h}$ in the ARS-Fp-R line as compared to the ARS-Fp-S line (Figure

$5 \mathrm{D}, \mathrm{E}$, Table S2). For illr-like-1(ex3-5), expression in the ARS-Fp-S line was lower at $6 \mathrm{~h}$ and 24h (Figure 5 F, Table S2) 


\section{Discussion}

The genetic control of fish disease resistance and the impact of selective breeding on immunological responsiveness remain poorly understood. Herein, we describe a new multiplex assay that measures a suite of immune-relevant genes and we used this assay to examine expression differences between PBS- and $F p$-injected fish from two genetic lines of rainbow trout exhibiting a well-characterized phenotypic difference in post-challenge survival. This study utilized juvenile rainbow trout in order to examine inter-individual and tissue-specific immunological responsiveness. We report gene expression differences occurring in the spleen, as part of a larger study examining gene expression differences occurring simultaneously within infiltrating peritoneal cavity cells and anterior kidney tissue, as well as, changes in plasma biochemistry and plasma proteins. We chose to initially investigate the spleen as it is a dynamic site of disease manifestation and substantial histological changes occur following $F p$ injection including an increased inflammatory infiltrate, perisplenitis, splenic necrosis, and increase in average and total splenic ellipsoid area [39]. The degree of perisplenitis and necrosis are higher in ARS-Fp-S line fish compared to ARS-Fp-R line fish, consistent with differential pathogen control [39]. The primary finding reported in this manuscript is the identification of fifteen differentially-regulated, immune-relevant genes following $F p$ challenge. These included the cytokines tnfa1, tnfa2, tnfa3, illb1, illb2, ill1a the putative receptors tnfrsfla, tnfrsfla-like-a, tnfrsfla-like-b, tnfrsf9, illr-like-1, illr1-like-b, illr2 as well as acute phase response genes saa and drtpl. Our previous study, measuring gene expression differences across the whole body, identified only a subset of these genes ( $\mathrm{n}=10)$ as differentially regulated including tnfal, illbl, ill1a, illr1-like-a, illr2, tnfrsfla, tnfrsfla-like-b, tnfrsf9, drtp1 and saa (Table S4), and it is likely that including an earlier sampling time point (6h) as well as sampling a specific tissue as 
compared to whole-body RNA-seq allowed detection of low abundance or rare cell-specific transcripts. In this study, we did not identify tnfrsf5(b) (GQ169788.1, GSONMT00012579001) as differentially regulated in contrast to our study of whole body gene expression and this difference remains unexplained. One possibility is that regulation occurred in a tissue other than the spleen or that fish size or developmental stage may be important $[49,50]$. This study identified two down-regulated genes, illr-like-1 and tnfrsfla-like-a, that exhibited differential expression between genetic lines. The measurement of individual fish sampled at the four early time-points allowed a temporal model of responsiveness and the dissection of differences between genetic lines.

\subsection{Interleukin and interleukin-receptor gene expression and kinetics}

Interleukin- $1 \beta$ is an early-response, pro-inflammatory cytokine [51, 52], and IL-1 family members also promote the adaptive immune response by enhancing the functions of B cells and the T helper cell subsets [53]. Two types of $i l l b$ genes are present in teleost fish [48]. Type I genes include $i l 1 b 3$ and $i l 1 b 4$, and type II genes include $i l 1 b 1$ and $i l 1 b 2[48,54]$. Our data identify early upregulation of $i l 1 b 1$ and $i l 1 b 2$ gene transcripts in the spleen following $F p$ challenge. This is consistent with previous reports of $i l l b 1$ and $i l 1 b 2$ upregulation in response to LPS and gram-negative bacterial pathogen challenge $[48,55]$. The expression of $i l 1 b 3$ has been less well studied. We report abundant illb3 basal gene expression but no upregulation in response to $F p$ exposure thus indicating differential control of gene expression compared to illbl and $i l 1 b 2$ paralogues. Basal illb3 expression has been previously reported to be relatively high in the spleen [48], and robust expression was detected in head-kidney macrophages exposed to LPS and in head-kidney tissue following VHSV infection [48]. A fourth paralogue, illb4 was 
previously identified as a pseudogene in Atlantic salmon [48]. Consistent with this possibility, illb4 gene expression in the rainbow trout whole-body RNA-Seq study revealed undetectable, or in a few samples, a very low number of mapped reads [24]. In this study we observe no detectable expression of $i l l b 4$ in spleen tissue in a sample size of 159 fish. In summary, our results are consistent with the proposed gene-expression sub-functionalization of $i l 1 b 1, i l 1 b 2$ and illb3 in response to different bacterial and viral pathogen challenge, and the loss of illb4 expression as a likely pseudogene [48], at least with respect to the fish species, populations and conditions studied.

In mammals, the response to interleukin-1 family members is initiated when a ligand binds to its primary receptor subunit, which for IL-1 is IL-1 receptor type I (IL-1R1). Ligand binding facilitates association of a second receptor subunit; the IL-1R accessory protein (IL-1RAP) and signaling is transmitted via dimerization of the TIR domains (reviewed in $[53,56]$ ). Regulation of the IL-1 receptor family is complex, with four activating receptors IL-1R1, IL-1RL2, ST2, and IL-18R as well as respective accessory proteins IL-1RAP and IL-18RAP, in addition to decoy receptors, receptor antagonists and binding proteins. Within this study, we identified 8 putative interleukin-1 receptor-related genes, and of these, 6 contained TIR domains (Table 1, Figure S3). We were able to design primers specific to 4 of these genes, with two primer-sets that crossamplified three highly-related genes sequences (GSONMT00035358001, GSONMT00021943001 and GSONMT00035357001). All three of these genes are located adjacent to one another on the same Chr Omy3 scaffold and thus likely represent a possibly recent, tandem duplication within the salmonid linage (Table S1). The gene encoding interleukin-1 receptor type 1-like (GSONMT00016995001) was not measured, nor was it previously identified as regulated [26]. In this study, due to the number and complexity of the 
interleukin-1 receptor accessory genes within the genome, we did not include primers to the 11 identified putative receptor accessory genes (Table S4), although we note that several are of interest as four (GSONMT00051039001, GSONMT00007860001, GSONMT00067362001, and GSONMT00029719001) were identified as regulated following challenge [26].

Mammalian IL-1 family member signaling is modulated by both receptor antagonists (IL1Ra) as well as membrane and soluble decoy receptors (IL-1R2, SIGIRR). In this manuscript, we identify illr2 (GSONMT00066304001) and illrl-like-b (GSONMT00032852001) genes as upregulated following $F p$ challenge. The trout ilr2 gene lacks a TIR domain [57] and thus may function as a decoy receptor consistent with the lack of a TIR domain in other fish species [5860] and upregulation in rainbow trout in response to bacterial infection [61]. Several putative receptor genes exhibited down-regulation following challenge. We identified Illrl-like-a (GSONMT00066303001) gene expression as down-regulated in our previous study using whole fish and also in this study, albeit to a limited extent, at the $48 \mathrm{~h}$ time point and in only the ARSFp-S line.

The most interesting down-regulated gene was illr-like-1 representing three sequence related, adjacent genes (GSONMT00035358001, GSONMT00021943001, GSONMT00035357001). The two primer sets used in this paper amplify across different regions of the three genes: either exons 3-5 or exons 9-11. The primers that amplify across exons 3-5 amplify 2 of the 3 sequence-related genes and have a 2 bp mismatch with gene GSONMT00021943001, while primers that amplify across exons 9-11 amplify all three genes. The amplification profiles using primer sets to exons 3-5 and 9-11 differed and it is likely that differential gene-set amplification and/or differences in expression between the three copies may explain these results. It is also possible that alternative splicing may contribute to these 
differences and the development of tools (primers or sequencing strategies) to distinguish between these gene copies is needed to resolve these possibilities. The predicted proteins share high (95-99\%) sequence identity to trout ST2L protein (CDG03205.1). Interestingly, the interleukin 1 receptor-like 1 gene (ST2L protein, 599aa) was previously identified as having 2.2fold lower expression in the rainbow trout strain BORN, a 37 year selection line bred in semiclosed aquaculture as compared to commercially-available Troutlodge strain (TCO) [62]. The BORN line is reported to exhibit higher survival following bacterial or viral challenge [62, 63]. The contribution of ST2L to the BORN line resistance phenotype is unknown as there were over 800 differentially-regulated genes between the two lines identified in spleen tissue from healthy animals. A ST2L homologue from Atlantic salmon (Salmo salar) is constitutively expressed in spleen, brain, blood cells, head kidney, liver, gills and muscle [64]. In vivo stimulation of salmon with bacterial lipopolysaccharide did not affect the expression of the salmon ST2L gene [64]. In this study, the expression of illr-like-1(ex9-11) was negatively correlated with expression of illb1 (-0.23), while expression levels of illrl-like-b and illr2 were positively correlated with both $i l 1 b 1$ ( 0.83 and 0.85 respectively) and $i l 1 b 2$ (0.62 and 0.59 respectively) (Table S3). In uninfected rainbow trout, we previously observed, using RNA-seq, that expression of the illrlike-1 gene (GSONMT00035358001) was highest in the ARS-Fp-R line, intermediated in the ARS-Fp-C line, and lowest in the ARS-Fp-S line fish consistent with the possibility that artificial selection for BCWD resistance may have led to increased basal gene expression [26]. It is notable that a previously identified BCWD QTL on Omy3 [65] has been recently localized within close proximity to these genes (Vallejo et al. unpublished data). The further characterization of the genomic location, ligand interaction(s), and protein abundance following $F p$ challenge is of future interest. 


\subsection{Tnf and tnfrsf gene expression.}

The TNF superfamily of ligands and receptors are critical immune response molecules involved in a number of biological activities including the canonical proinflammatory response in teleost fish $[52,66,67]$. Teleost fish can have multiple tumor necrosis factor encoding genes [67], and three tnfa genes have been reported in rainbow trout: tnfal, tnfa2, and tnfa3 [47]. In this study, expression of all three trout tumor necrosis factor genes were upregulated following Fp challenge, albeit the tnfa2 gene exhibited weaker up-regulation and a different pattern compared to tnfal and tnfa3 (Figure 2). The tnfa3 protein sequence is more distantly related to tnfa1 and tnfa 2 proteins suggesting the potential for subfunctionalization, although all three genes are upregulated in response to LPS or following bacterial challenge with the gramnegative pathogen $Y$. ruckeri [47]. Tnfa3 gene expression was found to be earlier and transiently expressed following either stimulation in the RTS-11 cells, in a mixed lymphocyte response, or following VHS virus challenge [47]. In this study, all three tnfa genes exhibited increased abundance by the earliest time-point measured, $6 \mathrm{~h}$ post-injection.

In humans, TNF exhibits high-affinity binding to two receptors, TNF-R1 (TNFRSF1A) and TNF-R2 (TNFRSF1B), whose major difference is the presence of a cytosolic death domain (present in TNF-R1) [68, 69]. The identification of the receptor(s) bound by rainbow trout tnfa gene products have not been unambiguously identified and analysis is complicated by a large family of at least 59 tnfrsf encoding genes (including partial genes) in the rainbow trout genome [26] and thus is more complicated than previously identified in zebrafish $n=33$ [67] and Fugu $\mathrm{n}=9$ [70]. We identified a select number of tnfrsf for further expression analysis based on sequence-based likelihood as candidate tnfa receptor(s) (Figure S4). One tnfrsfla and two 
tnfrsfla-like genes are present in the genome with associated death domains, albeit GSONMT00061855001 is likely either an incompletely assembled gene, a pseudogene, or an inhibitory receptor due to the partial sequence and presence of a death domain (Figure S4). The gene tnfrsfla is expressed at high levels in the spleen (see Table 2 in [44]) and whole body (Table S4) consistent with the expression of the TNFRl gene product which is present on most mammalian cell types. The three genes exhibit differential patterns of expression following challenge: tnfrsfla and tnfrsfla-like- $b$ are up-regulated while tnfrsfla-like- $a$ is down-regulated in the spleen (Figure 2). Two putative tnfrsflb receptor orthologues were identified, both of which lack death domains (Figure S4), but expression was not quantified in this study. In our prior analyses of these genes, both were expressed at low level (see Table 2 in [44]) and were not regulated following Fp challenge [26].

In this paper, we confirm that tnfrsf 9 exhibits robust up-regulation following challenge (Figure 2). This gene is a putative orthologue of the mammalian receptor gene encoding 4-1BB. In mammals, this protein functions as a co-stimulatory molecule expressed on activated $\mathrm{T}$ cells, dendritic cells, NK cells, and granulocytes. A putative ligand, identified in several fish species, clusters phylogenetically with mammalian 4-1BBL but a clear orthologue, to our knowledge, has not been identified in rainbow trout [71]. The function of these proteins in salmonid fish is unknown.

\subsection{Expression of acute phase response genes saa and drtpl}

The acute phase response (APR) and the inflammatory response are overlapping components of the reaction to infection and injury $[27,72]$. In humans, the pro-inflammatory SAA is a major acute phase protein (APP), whose expression is induced by inflammatory cytokines IL1B, IL6 
and TNF $[73,74]$. SAA is involved in diverse defensive functions, such as induction of cytokine synthesis, leukocyte recruitment, activation of epithelial cell immunity, neutrophil priming, opsonization of Gram-negative bacteria, activation of antimicrobial functions in polymorphonuclear cells and antiviral activity [75-82]. In rainbow trout it is upregulated after stimulation with LPS as well as during infection with gram-negative pathogens including $F p$ [55, $83,84]$. In the present study, expression level of saa was upregulated early (6h) in both trout lines and remained high at all time-points (Figure 3). Increased expression of saa in the peritoneal cavity of rainbow trout during infection with Aeromonas salmonicida correlated with the increased level of $i l 1 b$ and tnfa and other acute phase proteins [85]. We found a similar significant and positive gene expression correlation between saa and the three tnfa genes as well as illb1 and illb2 gene expression (Table S3).

Drtp1 belongs to APR and may participate in phospholipase inhibition, pathogen response, and the stress reaction [86]. Previously, it was shown that $d r t p l$ gene expression level increased in the liver of ayu (Plecoglossus altivelis) during Listonella anguillarum infection [87]. In Atlantic salmon, drtpl is upregulated in the gill, liver, spleen and head kidney after challenge with the bacterial pathogen $A$. salmonicida $[88,89]$. In this study, the level of $d r t p 1$ increased following $F p$ injection. However, drtpl expression level in ARS-Fp-S line increased earlier (24h) as compared to the ARS-Fp-R line (48h).

\section{Conclusion}

The GeXP assay described here is a cost-effective method for simultaneous measurement of transcript abundance of multiple immune-relevant genes and useful for confirming gene expression signatures identified by RNA-seq as well as for examining inter-individual variation 
in responsiveness to pathogen exposure. Herein, we described 15 differentially-regulated genes of which 13 were upregulated in response to $F p$ challenge, and these exhibited four general patterns of gene expression over the six day time period (Figure 2). Principle component analysis of variation, discriminating between the ARS-Fp-R and ARS-Fp-S lines, identified higher basal gene expression levels of three putative cytokine receptors tnfrsfla-like-a, and illr like-1 in the ARS-Fp-R line, as well as less down-regulation following challenge. Our working model is that the ARS-Fp- $\mathrm{R}$ line has more beneficial response, not due to greater proinflammatory cytokine gene expression, but possibly due to higher transcript abundance of putative cytokine receptors, albeit these may be decoy receptors. While variable between individual fish, pathogen load increases to higher mean levels in ARS-Fp-S line fish following challenge and it is not unexpected that we observed differences between genetic lines in the APR response (saa and drtp1), cytokine receptor (illr2, illr1-like-b, and tnfrsf9) and cytokine (illb1) gene transcript abundance that correlated with elevated pathogen load. Consistent with other reports, the induction of proinflammatory genes tnfal-3 and illbl-2 and putative antiinflammatory ill la temporally precedes the elevated transcript abundance of saa and $d r t p 1$.

An important caveat of this study is that we selected gene candidates based on primary sequence comparison, automated annotation and previous expression analyses using whole fish. Detailed evolutionary and functional analyses remain to confirm these are functional receptors (or decoys) as well as receptor accessory proteins implied by the automated annotation nomenclature. Furthermore, several of the genes we measured in this study (i.e. illr-like-l) were incompletely assembled in the current version of the rainbow trout genome (32) and it is likely that genes models will continue to be modified as improvements are made to the genome assembly. Finally, our analyses do not rule out changes in infiltrating cells (or exit of cells) 
accounting for differences in gene expression. Our current approach to confirm the relationship of the identified differentially expressed genes with the disease resistance phenotype is through continued fine-mapping of BCWD quantitative trait loci [65, 90-93]. 


\section{Acknowledgements}

The authors would like to thank Joel Caren and Keira Osbourn for assisting with sample and data collection. This work was supported by Agriculture and Food Research Initiative competitive grant no. 2012-67015-30217 from the USDA National Institute of Food and Agriculture and by Agricultural Research Service CRIS Project 1930-32000-006 “Integrated Research to Improve On-Farm Animal health in Salmonid Aquaculture". Support was also received from the 20142015 Russian Fulbright Visiting Scholar Program awarded to IK and the Russian Foundation for Basic Research (project no. 16-04-01213). This study was performed under the project of the Siberian Branch of the Russian Academy of Sciences, VI.51.1.3. Mention of trade names or commercial products in this publication is solely for the purpose of providing specific information and does not imply recommendation or endorsement by the U.S Department of Agriculture. USDA is an equal opportunity employer. 


\section{References}

1. Cock J, Gitterle T, Salazar M, Rye M. Breeding for disease resistance of Penaeid shrimps. Aquaculture. 2009 286:1-11.

2. Gjedrem T. Genetic variation in quantitative traits and selective breeding in fish and shellfish. Aquaculture. 1983 33:51-71.

3. Gjedrem T. Selection and breeding programs in aquaculture: Springer; 2005.

4. Gjedrem T, Robinson N, Rye M. The importance of selective breeding in aquaculture to meet future demands for animal protein: A review. Aquaculture. 2012 350-353:117-29.

5. Van Muiswinkel WB, Wiegertjes GF, Stet RJM. The influence of environmental and genetic factors on the disease resistance of fish. Aquaculture. 1999 172:103-10.

6. Silverstein JT, Vallejo RL, Palti Y, Leeds TD, Rexroad CE, 3rd, Welch TJ, et al. Rainbow trout resistance to bacterial cold-water disease is moderately heritable and is not adversely correlated with growth. J Anim Sci. 2009 87:860-7.

7. Barnes ME, Brown ML. A review of Flavobacterium psychrophilum biology, clinical signs, and bacterial cold water disease prevention and treatment. The Open Fish Sci J. 2011 4:19.

8. Nematollahi A, Decostere A, Pasmans F, Haesebrouck F. Flavobacterium psychrophilum infections in salmonid fish. J Fish Dis. 2003 26:563-74.

9. Gómez E, Méndez J, Cascales D, Guijarro JA. Flavobacterium psychrophilum vaccine development: a difficult task. Microbial Biotechnology. 2014 7:414-23.

10. Sundell K, Högfors-Rönnholm E, Wiklund T. 23 Vaccination against Diseases Caused by Flavobacteriaceae Species. In: Roar Gudding AL, Oystein Evensen, editor. Fish Vaccination: Wiley Blackwell; 2014, p. 273-82.

11. Hadidi S, Glenney GW, Welch TJ, Silverstein JT, Wiens GD. Spleen size predicts resistance of rainbow trout to Flavobacterium psychrophilum challenge. J Immunol. 2008 180:4156-65.

12. Leeds TD, Silverstein JT, Weber GM, Vallejo RL, Palti Y, Rexroad CE, 3rd, et al. Response to selection for bacterial cold water disease resistance in rainbow trout. J Anim Sci. 2010 88:1936-46.

13. Wiens GD, LaPatra SE, Welch TJ, Evenhuis JP, Rexroad III CE, Leeds TD. On-farm performance of rainbow trout (Oncorhynchus mykiss) selectively bred for resistance to bacterial cold water disease: Effect of rearing environment on survival phenotype. Aquaculture. 2013:12836.

14. Wiens GD, Leeds TD, LaPatra SE, Wilson C, Cavendar W, Rexroad CE, 3rd. Field evaluation of rainbow trout selectively bred for resistance to bacterial cold water disease. . Flavobacterium 2012 Arken, Turku, Finland; 2012.

15. Baerwald MR. Temporal expression patterns of rainbow trout immune-related genes in response to Myxobolus cerebralis exposure. Fish Shellfish Immunol. 2013 35:965-71.

16. Baoprasertkul P, Peatman E, Chen L, He C, Kucuktas H, Li P, et al. Sequence analysis and expression of a CXC chemokine in resistant and susceptible catfish after infection of Edwardsiella ictaluri. Dev Comp Immunol. 2004 28:769-80.

17. Cofre C, Gonzalez R, Moya J, Vidal R. Phenotype gene expression differences between resistant and susceptible salmon families to IPNV. Fish Physiol Biochem. 2014 40:887-96.

18. Dettleff P, Bravo C, Patel A, Martinez V. Patterns of Piscirickettsia salmonis load in susceptible and resistant families of Salmo salar. Fish Shellfish Immunol. 2015 45:67-71. 
19. Diaz-Rosales P, Romero A, Balseiro P, Dios S, Novoa B, Figueras A. Microarray-based identification of differentially expressed genes in families of turbot (Scophthalmus maximus) after infection with viral haemorrhagic septicaemia virus (VHSV). Mar Biotechnol (NY). 2012 14:515-29.

20. Holm H, Santi N, Kjoglum S, Perisic N, Skugor S, Evensen O. Difference in skin immune responses to infection with salmon louse (Lepeophtheirus salmonis) in Atlantic salmon (Salmo salar L.) of families selected for resistance and susceptibility. Fish Shellfish Immunol. 2015 42:384-94.

21. Langevin C, Blanco M, Martin SA, Jouneau L, Bernardet JF, Houel A, et al. Transcriptional responses of resistant and susceptible fish clones to the bacterial pathogen Flavobacterium psychrophilum. PLoS One. 2012 7:e39126.

22. Reyes-Lopez FE, Romeo JS, Vallejos-Vidal E, Reyes-Cerpa S, Sandino AM, Tort L, et al. Differential immune gene expression profiles in susceptible and resistant full-sibling families of Atlantic salmon (Salmo salar) challenged with infectious pancreatic necrosis virus (IPNV). Dev Comp Immunol. 2015 53:210-21.

23. Sahoo PK, Das S, Mahapatra KD, Saha JN, Baranski M, Odegard J, et al. Characterization of the ceruloplasmin gene and its potential role as an indirect marker for selection to Aeromonas hydrophila resistance in rohu, Labeo rohita. Fish Shellfish Immunol. 2013 34:1325-34.

24. Sutherland BJ, Koczka KW, Yasuike M, Jantzen SG, Yazawa R, Koop BF, et al. Comparative transcriptomics of Atlantic Salmo salar, chum Oncorhynchus keta and pink salmon O. gorbuscha during infections with salmon lice Lepeophtheirus salmonis. BMC Genomics. 2014 15:200.

25. Zhang Z, Niu C, Storset A, Bogwald J, Dalmo RA. Comparison of Aeromonas salmonicida resistant and susceptible salmon families: a high immune response is beneficial for the survival against Aeromonas salmonicida challenge. Fish Shellfish Immunol. 2011 31:1-9. 26. Marancik D, Gao G, Paneru B, Ma H, Hernandez AG, Salem M, et al. Whole-body transcriptome of selectively bred, resistant-, control-, and susceptible-line rainbow trout following experimental challenge with Flavobacterium psychrophilum. Front Genet. 2015 5:453. 27. Bayne CJ, Gerwick L. The acute phase response and innate immunity of fish. Dev Comp Immunol. 2001 25:725-43.

28. Cray C. Acute phase proteins in animals. Prog Mol Biol Transl Sci. 2012 105:113-50.

29. Cray C, Zaias J, Altman NH. Acute phase response in animals: a review. Comp Med. 2009 59:517-26.

30. Alexander HR, Doherty GM, Buresh CM, Venzon DJ, Norton JA. A recombinant human receptor antagonist to interleukin 1 improves survival after lethal endotoxemia in mice. J Exp Med. 1991 173:1029-32.

31. Tracey KJ, Fong Y, Hesse DG, Manogue KR, Lee AT, Kuo GC, et al. Anticachectin/TNF monoclonal antibodies prevent septic shock during lethal bacteraemia. Nature. 1987 330:662-4.

32. Berthelot C, Brunet F, Chalopin D, Juanchich A, Bernard M, Noel B, et al. The rainbow trout genome provides novel insights into evolution after whole-genome duplication in vertebrates. Nat Commun. 2014 5:3657.

33. Moghadam HK, Ferguson MM, Danzmann RG. Whole genome duplication: challenges and considerations associated with sequence orthology assignment in Salmoninae. J Fish Biol. 2011 79:561-74. 
34. Warren IA, Ciborowski KL, Casadei E, Hazlerigg DG, Martin S, Jordan WC, et al. Extensive local gene duplication and functional divergence among paralogs in Atlantic salmon. Genome Biol Evol. 2014 6:1790-805.

35. Rai AJ, Kamath RM, Gerald W, Fleisher M. Analytical validation of the GeXP analyzer and design of a workflow for cancer-biomarker discovery using multiplexed gene-expression profiling. Anal Bioanal Chem. 2009 393:1505-11.

36. Biswas G, Korenaga H, Nagamine R, Takayama H, Kawahara S, Takeda S, et al. Cytokine responses in the Japanese pufferfish (Takifugu rubripes) head kidney cells induced with heat-killed probiotics isolated from the Mongolian dairy products. Fish Shellfish Immunol. 2013 34:1170-7.

37. Wang T, Holland JW, Bols N, Secombes CJ. Cloning and expression of the first nonmammalian interleukin-11 gene in rainbow trout Oncorhynchus mykiss. FEBS J. 2005 272:1136-47.

38. Wiens GD, LaPatra SE, Welch TJ, Evenhuis JP, Rexroad CE, 3rd, Leeds TD. On-farm performance of rainbow trout (Oncorhynchus mykiss) selectively bred for resistance to bacterial cold water disease: Effect of rearing environment on survival phenotype. Aquaculture. 2013 388391:128-36.

39. Marancik DP, Leeds TD, Wiens GD. Histopathologic changes in disease-resistant-line and disease-susceptible-line juvenile rainbow trout experimentally infected with Flavobacterium psychrophilum. J Aquat Anim Health. 2014 26:181-9.

40. Wiens GD, LaPatra SE, Welch TJ, Rexroad C, 3rd, Call DR, Cain KD, et al. Complete genome sequence of Flavobacterium psychrophilum strain CSF259-93, used to select rainbow trout for increased genetic resistance against bacterial cold water disease. Genome Announc. 20142.

41. Marancik DP, Camus MS, Camus AC, Leeds TD, Weber GM, Wiens GD. Biochemical reference intervals and pathophysiological changes in Flavobacterium psychrophilum-resistant and -susceptible rainbow trout lines. Dis Aquat Organ. 2014 111:239-48.

42. Marancik DP, Wiens GD. A real-time polymerase chain reaction assay for identification and quantification of Flavobacterium psychrophilum and application to disease resistance studies in selectively bred rainbow trout Oncorhynchus mykiss. FEMS Microbiol Lett. 2013 339:122-9. 43. Croghan C, Egeghy PP. Methods of dealing with values below the limit of detection using SAS. Southern SAS User Group; 2003, p. 22-4.

44. Kutyrev I, Cleveland BJ, Leeds TD, Wiens GD. Dataset of proinflammatory cytokine and cytokine receptor gene expression in rainbow trout (Oncorhynchus mykiss) measured using a novel GeXP multiplex, RT-PCR assay. . Data in Brief. 2016.

45. Cleveland BM, Weber GM. Effects of sex steroids on expression of genes regulating growth-related mechanisms in rainbow trout (Oncorhynchus mykiss). Gen Comp Endocrinol. 2015 216:103-15.

46. Cleveland BM, Weber GM. Effects of steroid treatment on growth, nutrient partitioning, and expression of genes related to growth and nutrient metabolism in adult triploid rainbow trout (Oncorhynchus mykiss). Domest Anim Endocrinol. 2016 56:1-12.

47. Hong S, Li R, Xu Q, Secombes CJ, Wang T. Two types of TNF-alpha exist in teleost fish: phylogeny, expression, and bioactivity analysis of type-II TNF-alpha3 in rainbow trout Oncorhynchus mykiss. J Immunol. 2013 191:5959-72. 
48. Husain M, Bird S, van Zwieten R, Secombes CJ, Wang T. Cloning of the IL-1beta3 gene and IL-1beta4 pseudogene in salmonids uncovers a second type of IL-1beta gene in teleost fish. Dev Comp Immunol. 2012 38:431-46.

49. Zapata A, Diez B, Cejalvo T, Gutierrez-de Frias C, Cortes A. Ontogeny of the immune system of fish. Fish Shellfish Immunol. 2006 20:126-36.

50. Rombout JH, Huttenhuis HB, Picchietti S, Scapigliati G. Phylogeny and ontogeny of fish leucocytes. Fish Shellfish Immunol. 2005 19:441-55.

51. Secombes CJ, Wang T, Bird S. The interleukins of fish. Dev Comp Immunol. 2011 35:1336-45.

52. Zhu LY, Nie L, Zhu G, Xiang LX, Shao JZ. Advances in research of fish immunerelevant genes: a comparative overview of innate and adaptive immunity in teleosts. Dev Comp Immunol. 2013 39:39-62.

53. Sims JE, Smith DE. The IL-1 family: regulators of immunity. Nat Rev Immunol. 2010 10:89-102.

54. Wang T, Bird S, Koussounadis A, Holland JW, Carrington A, Zou J, et al. Identification of a novel IL-1 cytokine family member in teleost fish. J Immunol. 2009 183:962-74.

55. Wiens GD, Vallejo RL. Temporal and pathogen-load dependent changes in rainbow trout (Oncorhynchus mykiss) immune response traits following challenge with biotype 2 Yersinia ruckeri. Fish Shellfish Immunol. 2010 29:639-47.

56. Zou J, Secombes CJ. The Function of Fish Cytokines. Biology (Basel). 20165.

57. Sangrador-Vegas A, Martin SA, O'Dea PG, Smith TJ. Cloning and characterization of the rainbow trout (Oncorhynchus mykiss) type II interleukin-1 receptor cDNA. Eur J Biochem. 2000 267:7031-7.

58. Fan Y, Li S, Qi J, Zeng L, Zhong Q, Zhang Q. Cloning and characterization of type II interleukin-1 receptor cDNA from Japanese flounder (Paralichthys olivaceus). Comp Biochem Physiol B Biochem Mol Biol. 2010 157:59-65.

59. Lopez-Castejon G, Sepulcre MP, Roca FJ, Castellana B, Planas JV, Meseguer J, et al. The type II interleukin-1 receptor (IL-1RII) of the bony fish gilthead seabream Sparus aurata is strongly induced after infection and tightly regulated at transcriptional and post-transcriptional levels. Mol Immunol. 2007 44:2772-80.

60. Yang X, Wang S, Du L, Yang K, Wang X, Zhang A, et al. Molecular and functional characterization of IL-1 receptor type 2 in grass carp: a potent inhibitor of IL-1beta signaling in head kidney leukocytes. Dev Comp Immunol. 2013 41:738-45.

61. Castro R, Jouneau L, Tacchi L, Macqueen DJ, Alzaid A, Secombes CJ, et al. Disparate developmental patterns of immune responses to bacterial and viral infections in fish. Sci Rep. 2015 5:15458.

62. Kobis JM, Rebl A, Kuhn C, Goldammer T. Comparison of splenic transcriptome activity of two rainbow trout strains differing in robustness under regional aquaculture conditions. Mol Biol Rep. 2013 40:1955-66.

63. Rebl A, Kobis JM, Fischer U, Takizawa F, Verleih M, Wimmers K, et al. MARCH5 gene is duplicated in rainbow trout, but only fish-specific gene copy is up-regulated after VHSV infection. Fish Shellfish Immunol. 2011 31:1041-50.

64. Subramaniam S, Stansberg C, Cunningham C. The interleukin 1 receptor family. Dev Comp Immunol. 2004 28:415-28. 
65. Vallejo RL, Palti Y, Liu S, Evenhuis JP, Gao G, Rexroad CE, 3rd, et al. Detection of QTL in rainbow trout affecting survival when challenged with Flavobacterium psychrophilum. Mar Biotechnol (NY). 2014 16:349-60.

66. Goetz FW, Planas JV, MacKenzie S. Tumor necrosis factors. Dev Comp Immunol. 2004 28:487-97.

67. Wiens GD, Glenney GW. Origin and evolution of TNF and TNF receptor superfamilies. Dev Comp Immunol. 2011 35:1324-35.

68. Lang I, Fullsack S, Wyzgol A, Fick A, Trebing J, Arana JA, et al. Binding studies of TNF receptor superfamily (TNFRSF) receptors on intact cells. J Biol Chem. 2016 291:5022-37.

69. Bossen C, Ingold K, Tardivel A, Bodmer JL, Gaide O, Hertig S, et al. Interactions of tumor necrosis factor (TNF) and TNF receptor family members in the mouse and human. J Biol Chem. 2006 281:13964-71.

70. Biswas G, Kinoshita S, Kono T, Hikima J, Sakai M. Evolutionary evidence of tumor necrosis factor super family members in the Japanese pufferfish (Takifugu rubripes): Comprehensive genomic identification and expression analysis. Mar Genomics. 2015 22:25-36. 71. Glenney GW, Wiens GD. Early diversification of the TNF superfamily in teleosts: genomic characterization and expression analysis. J Immunol. 2007 178:7955-73.

72. Gruys E, Toussaint MJ, Upragarin N, Van EA, Adewuyi AA, Candiani D, et al. Acute phase reactants, challenge in the near future of animal production and veterinary medicine. $J$ Zhejiang Univ Sci B. 2005 6:941-7.

73. Jensen LE, Whitehead AS. Regulation of serum amyloid A protein expression during the acute-phase response. Biochem J. 1998334 ( Pt 3):489-503.

74. Schmidt U, Wagner H, Miethke T. CpG-DNA upregulates the major acute-phase proteins SAA and SAP. Cell Microbiol. 1999 1:61-7.

75. Shah C, Hari-Dass R, Raynes JG. Serum amyloid A is an innate immune opsonin for Gram-negative bacteria. Blood. 2006 108:1751-7.

76. Patel H, Fellowes R, Coade S, Woo P. Human serum amyloid A has cytokine-like properties. Scand J Immunol. 1998 48:410-8.

77. Mullan RH, Bresnihan B, Golden-Mason L, Markham T, O'Hara R, FitzGerald O, et al. Acute-phase serum amyloid A stimulation of angiogenesis, leukocyte recruitment, and matrix degradation in rheumatoid arthritis through an NF-kappaB-dependent signal transduction pathway. Arthritis Rheum. 2006 54:105-14.

78. Lavie M, Voisset C, Vu-Dac N, Zurawski V, Duverlie G, Wychowski C, et al. Serum amyloid $\mathrm{A}$ has antiviral activity against hepatitis $\mathrm{C}$ virus by inhibiting virus entry in a cell culture system. Hepatology. 2006 44:1626-34.

79. Hatanaka E, Pereira Ribeiro F, Campa A. The acute phase protein serum amyloid A primes neutrophils. FEMS Immunol Med Microbiol. 2003 38:81-4.

80. Fukushima K, Ogawa H, Kitayama T, Yamada T, Naito H, Funayama Y, et al. Epithelial induction of serum amyloid A in experimental mucosal inflammation. Dig Dis Sci. 2002 47:1438-46.

81. Cai Z, Cai L, Jiang J, Chang KS, van der Westhuyzen DR, Luo G. Human serum amyloid A protein inhibits hepatitis C virus entry into cells. J Virol. 2007 81:6128-33.

82. Badolato R, Wang JM, Stornello SL, Ponzi AN, Duse M, Musso T. Serum amyloid A is an activator of PMN antimicrobial functions: induction of degranulation, phagocytosis, and enhancement of anti-Candida activity. J Leukoc Biol. 2000 67:381-6. 
83. Evenhuis JP, Cleveland BM. Modulation of rainbow trout (Oncorhynchus mykiss) intestinal immune gene expression following bacterial challenge. Vet Immunol Immunopathol. 2012 146:8-17.

84. Villarroel F, Casado A, Vasquez J, Matamala E, Araneda B, Amthauer R, et al. Serum amyloid A: a typical acute-phase reactant in rainbow trout? Dev Comp Immunol. 2008 32:11609.

85. Korytar T, Jaros J, Verleih M, Rebl A, Kotterba G, Kuhn C, et al. Novel insights into the peritoneal inflammation of rainbow trout (Oncorhynchus mykiss). Fish Shellfish Immunol. 2013 35:1192-9.

86. Talbot AT, Smith TJ, Cairns MT. Characterisation of the differentially regulated trout protein 1 (DRTP1) gene in rainbow trout (Oncorhynchus mykiss). Fish Shellfish Immunol. 2009 26:589-98.

87. $\quad \mathrm{Li} \mathrm{CH}$, Chen J, Shi YH, Lu XJ. Use of suppressive subtractive hybridization to identify differentially expressed genes in ayu (Plecoglossus altivelis) associated with Listonella anguillarum infection. Fish Shellfish Immunol. 2011 31:500-6.

88. Martin SA, Blaney SC, Houlihan DF, Secombes CJ. Transcriptome response following administration of a live bacterial vaccine in Atlantic salmon (Salmo salar). Mol Immunol. 2006 43:1900-11.

89. Tsoi SC, Ewart KV, Penny S, Melville K, Liebscher RS, Brown LL, et al. Identification of immune-relevant genes from atlantic salmon using suppression subtractive hybridization. Mar Biotechnol (NY). 2004 6:199-214.

90. Liu S, Vallejo RL, Palti Y, Gao G, Marancik DP, Hernandez AG, et al. Identification of single nucleotide polymorphism markers associated with bacterial cold water disease resistance and spleen size in rainbow trout. Front Genet. 2015 6:298.

91. Palti Y, Vallejo RL, Gao G, Liu S, Hernandez AG, Rexroad CE, 3rd, et al. Detection and validation of QTL affecting bacterial cold water disease resistance in rainbow trout using restriction-site associated DNA sequencing. PLoS One. 2015 10:e0138435.

92. Vallejo RL, Palti Y, Liu S, Marancik DP, Wiens GD. Validation of linked QTL for bacterial cold water disease resistance and spleen size on rainbow trout chromosome Omy 19. Aquaculture. 2014 432:139-43.

93. Wiens GD, Vallejo RL, Leeds TD, Palti Y, Hadidi S, Liu S, et al. Assessment of genetic correlation between bacterial cold water disease resistance and spleen index in a domesticated population of rainbow trout: identification of QTL on chromosome Omy 19. PLoS One. 2013 8:e75749. 


\section{Figure Captions}

Figure 1. Comparison of $F p$ load in spleen tissue between ARS-Fp-R and $-\mathrm{S}$ line fish at 6, 24, 48h and $144 \mathrm{~h}$ post-injection challenge. Values represent mean $F p$ GE $100 \mathrm{ng} \mathrm{DNA}^{-1}( \pm 1 \mathrm{SEM}$, n=10 fish). Two-way ANOVA identified a significant effect of time and genetic line. Pair-wise comparison at each of the 4 time points identified a significant difference in $F p$ load at $48 \mathrm{~h}$ between genetic lines $(P<0.05)$. n.s. $=$ not significant.

Figure 2. Heat map showing normalized gene expression of significantly regulated genes in spleen tissue of $F p$ injection-challenged and PBS-injected fish. Yellow heat-map bars represents higher gene expression and blue bars lower gene expression in individual fish $(\mathrm{n}=156)$. Differentially regulated genes (listed to right) were identified by principal component analysis as exhibiting >2-fold expression difference between infected and PBS injected animals with a false discovery rate of $(\mathrm{q}=0.05)$ and are ordered by hierarchical clustering (left). The top track represents pathogen load measured by qPCR and expressed as Fp GE $100 \mathrm{ng} \mathrm{DNA}^{-1}$. Legend above the heat-map shows time post-injection (h), genetic line (ARS-Fp-R line, blue; ARS-Fp-S line, red), fish infection status (PBS-injected, yellow; Fp-injected, orange). Genes are divided into five groups based on their overall expression pattern.

Figure 3. Comparison of gene expression (GE) kinetics between $F p$ injected with PBS injected fish by genetic line. Genes saa (panels A, B), drtpl (panels C, D), illr2 (panels E, F), illrl-like$b$ (panels G, H), tnfrsf9 (panels I, J), tnfal (panels K, L), tnfa2 (panels M, N), tnfa3 (panels O, P), illb1 (panels Q, R), illb2 (panels S, T), tnfrsfla (panels U, V), tnfrsfla-like-b (panels W, X). Data are from the ARS-Fp-R line (panels A, C, E, G, I, K, M, O, Q, S, U, W) and ARS-Fp-S line 
(B, D, F, H, J, L, N, P, R, T, V, X). In each graph, Fp-challenged fish are denoted by a solid line, PBS-injected fish are indicated by a dashed line. The results represent the mean $\left(\log _{2}\right) \pm 1$ SEM. Asterisk annotation: $* P<0.05 ; * * P<0.01 ; * * * P<0.001$; and $* * * * P<0.0001$.

Figure 4. Identification of significantly regulated genes between genetic lines using principal component analysis ( $>2$-foldcut-off and false discovery rate $q=0.05$ ). Legend above the figure denotes individual fish (ARS-Fp-R line, blue color; ARS-Fp-S line, red color). Variables, genes and spleen size measurements, are grouped by hierarchal clustering. Individual fish are ordered along the horizontal, based on PCA1 values which account for $40 \%$ of the variation.

Figure 5. Differences in gene expression of tnfrsfla-like-a (A, D), illr-like-1(exons3-5) (B, E), illr-like-1(exons9-11) (C, F) between ARS-Fp-R and ARS-Fp-S lines. The results represent the mean $\left(\log _{2}\right) \pm 1$ SEM. A-C) comparison between PBS injected fish from both lines. D-F) comparison between lines of $F p$ challenged fish (solid line, ARS-Fp-R line; dashed line, ARSFp-S line). Asterisk annotation: $* P<0.05$; and $* * P<0.01$. 


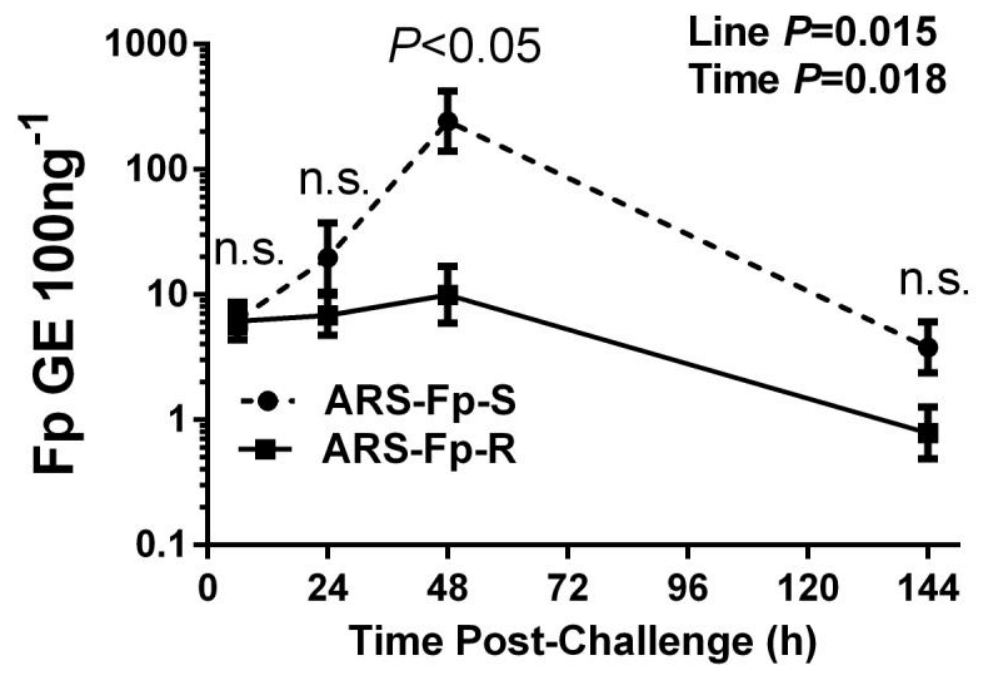




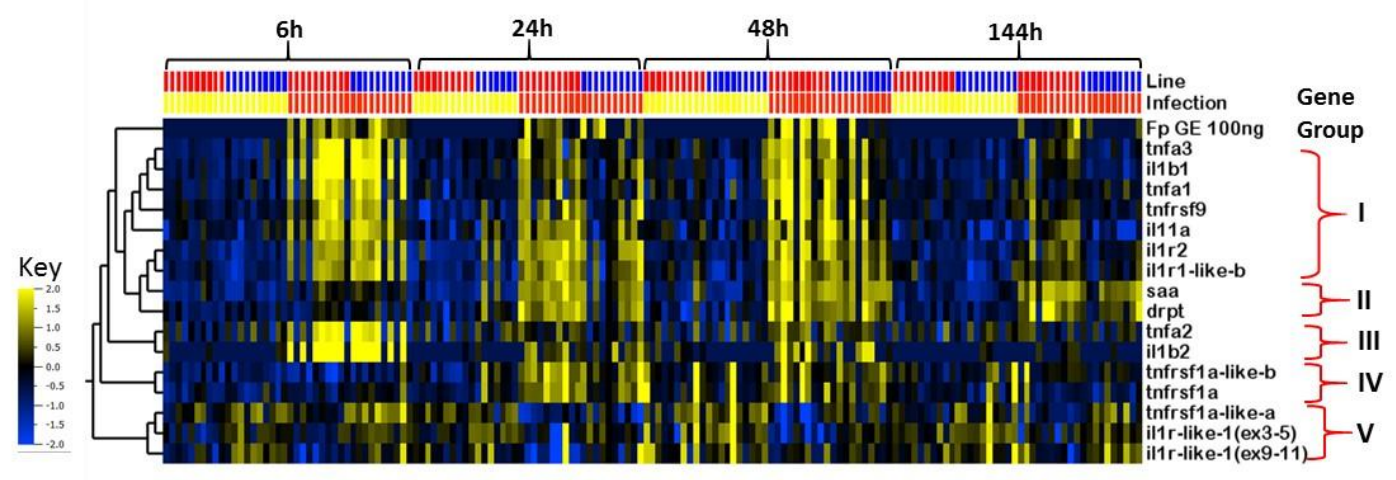


ARS-Fp-R
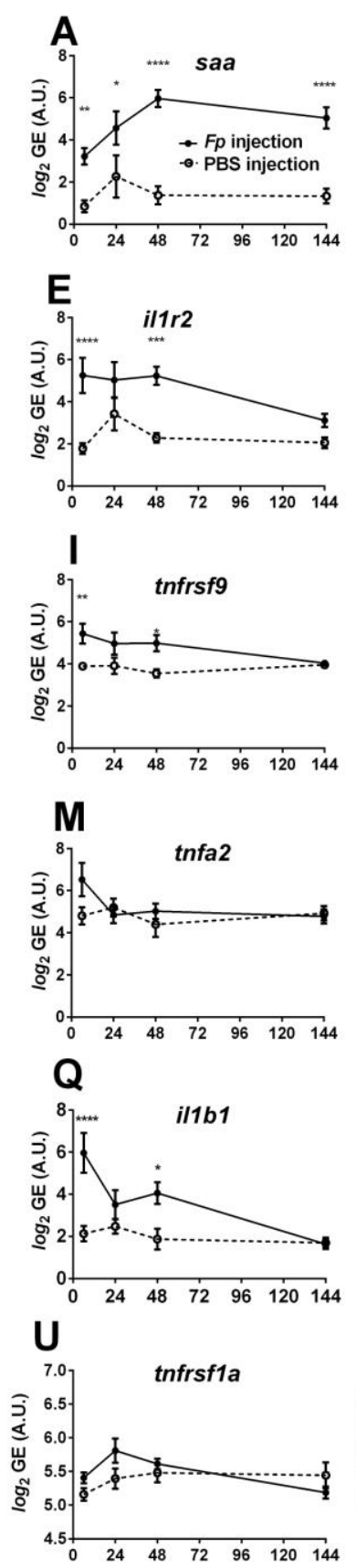
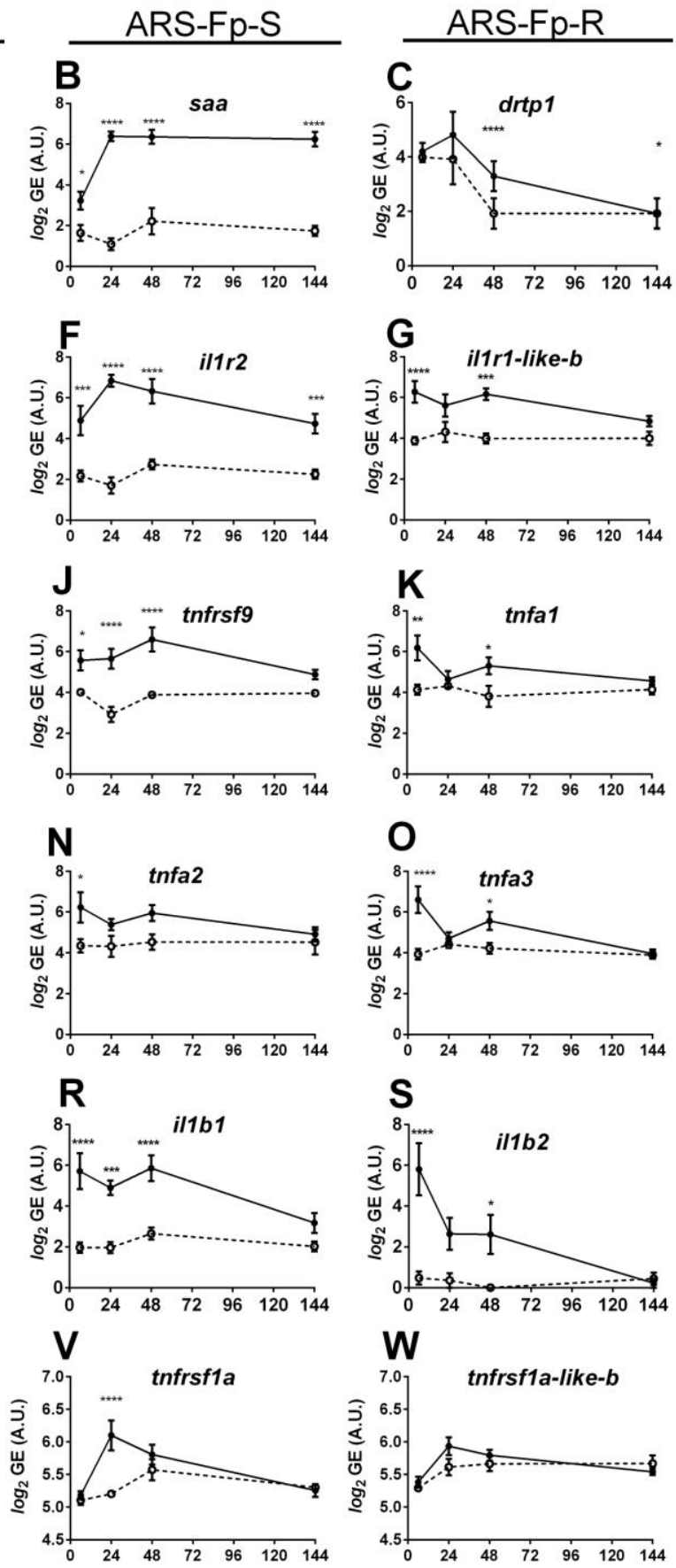
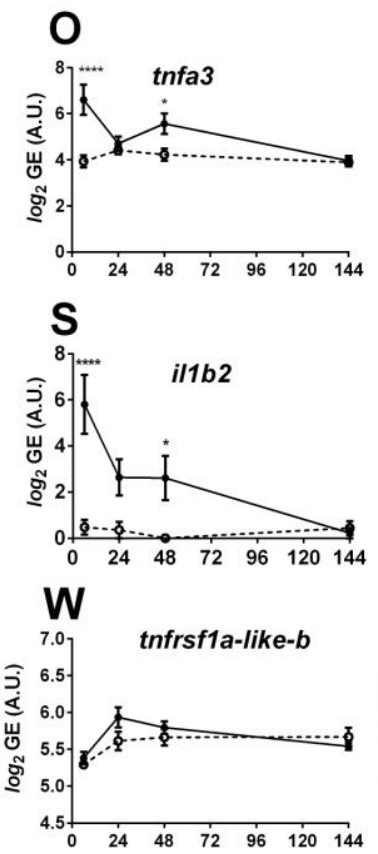
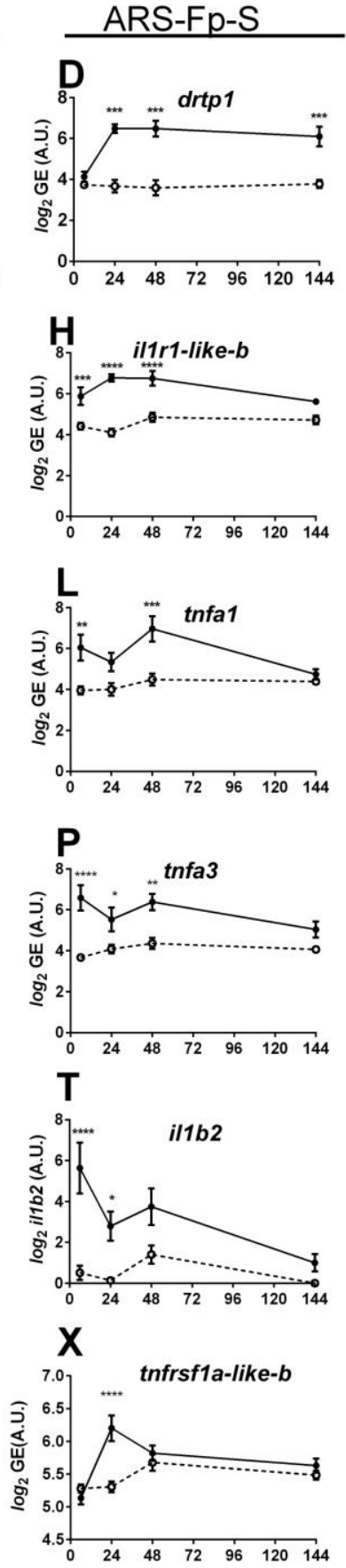

Time Post-Challenge (h) 


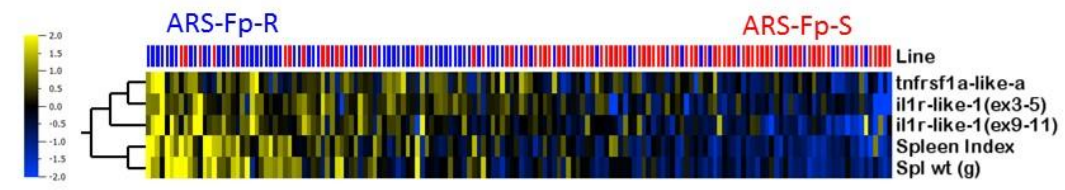



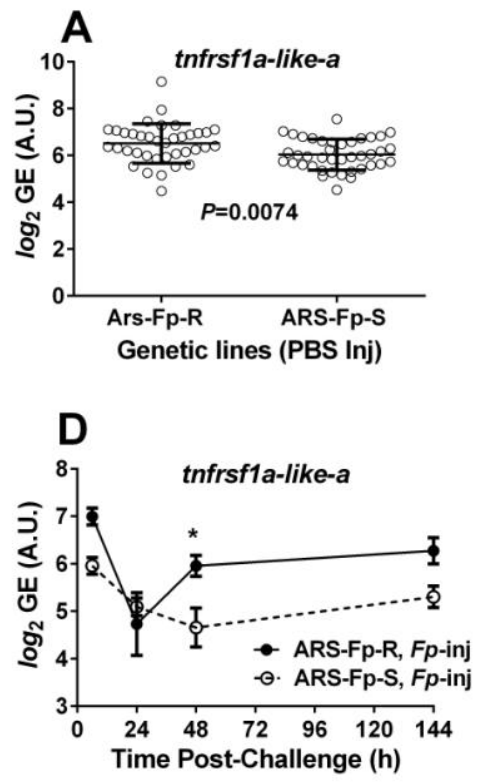
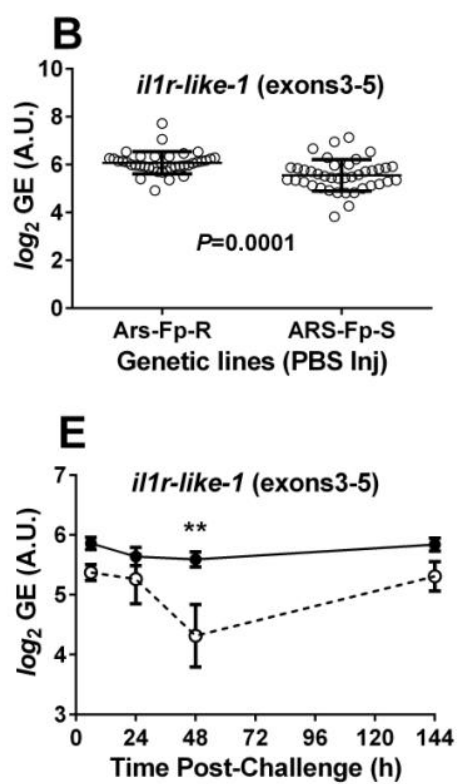
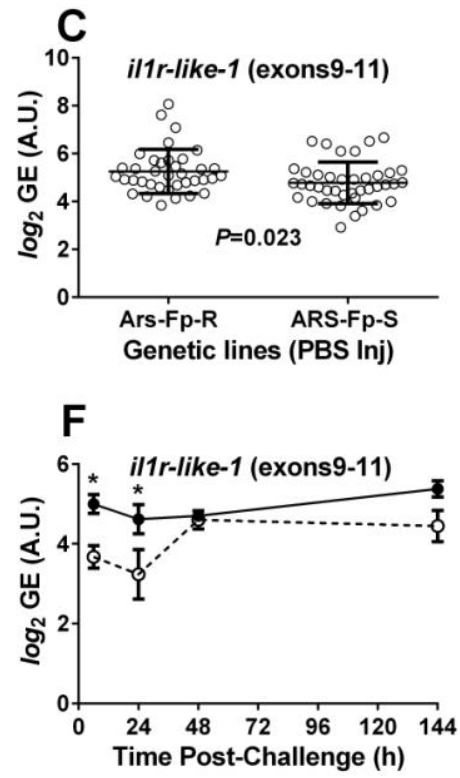
Table 1. Immune relevant and house-keeping genes targeted by the PCR multiplex assay.

\begin{tabular}{|c|c|c|c|c|}
\hline Category & Gene/Protein Description & $\begin{array}{c}\text { Gene } \\
\text { Abbreviation }\end{array}$ & $\begin{array}{c}\text { Accession \# or } \\
\text { Genome locus transcript }\end{array}$ & $\begin{array}{l}\text { PCR } \\
\text { Product(bp) }\end{array}$ \\
\hline \multirow{2}{*}{$\begin{array}{l}\text { Acute Phase } \\
\text { Protein }\end{array}$} & serum amyloid $\mathrm{A}$ & $s a a$ & GSONMT00016296001 & 247 \\
\hline & $\begin{array}{c}\text { differentially regulated protein } 1 \\
\text { precursor }\end{array}$ & drtpl & GSONMT00048193001 & 151 \\
\hline \multirow{5}{*}{$\begin{array}{l}\text { Interleukins } \\
\text { (IL) }\end{array}$} & interleukin- 1 beta- 1 & $i l 1 b 1$ & NM_001124347 & 223 \\
\hline & interleukin- 1 beta- 2 & $i l 1 b 2$ & AJ245925 & 279 \\
\hline & interleukin- 1 beta-3 & $i l 1 b 3$ & AJ557021 & 232 \\
\hline & interleukin- 1 beta 4 (pseudogene) & $i l 1 b 4$ & GSONMT00003908001 & 179 \\
\hline & interleukin-11a & ill1a & GSONMT00009406001 & 251 \\
\hline \multirow[t]{5}{*}{ IL-receptors } & $\begin{array}{l}\text { interleukin- } 1 \text { receptor-like } 1^{1} \\
\text { interleukin-1 receptor-like } 1 \\
\text { interleukin- } 1 \text { receptor-like } 1\end{array}$ & $\begin{array}{l}\text { illr-like-1 } \\
\text { (Exons 9-11) }\end{array}$ & $\begin{array}{l}\text { GSONMT00035358001 } \\
\text { GSONMT00021943001 } \\
\text { GSONMT00035357001 }\end{array}$ & 168 \\
\hline & interleukin-1 receptor-like $1^{2}$ & $\begin{array}{l}\text { illr-like-1 } \\
\text { (Exons 3-5) }\end{array}$ & GSONMT00022297001 & 307 \\
\hline & interleukin-1 receptor type 1-like & illrl-like-a ${ }^{3}$ & GSONMT00066303001 & 238 \\
\hline & interleukin-1 receptor type 1-like & illrl-like- $b^{3}$ & GSONMT00032852001 & 241 \\
\hline & interleukin- 1 receptor type $2^{4}$ & $i l 1 r 2$ & GSONMT00066304001 & 270 \\
\hline \multirow{3}{*}{$\begin{array}{l}\text { TNF } \\
\text { superfamily }\end{array}$} & tumor necrosis factor alpha 1 & tnfal & NM_001124357 & 136 \\
\hline & tumor necrosis factor alpha 2 & $\operatorname{tnfa2}$ & NM_001124374 & 143 \\
\hline & tumor necrosis factor alpha 3 & tnfa3 & HE798544 & 184 \\
\hline \multirow{6}{*}{$\begin{array}{l}\text { TNF receptor } \\
\text { superfamily }\end{array}$} & tnf receptor superfamily $1 \mathrm{a}$ & tnfrsfla & GSONMT00019008001 & 349 \\
\hline & tnf receptor superfamily 1a like & tnfrsfla-like- $a^{3}$ & GSONMT00061855001 & 175 \\
\hline & tnf receptor superfamily 1a like & tnfrsfla-like- $b^{3}$ & GSONMT00061996001 & 337 \\
\hline & tnf receptor superfamily $1 \mathrm{~b}$ & tnfrsflb & GSONMT00074093001 & 147 \\
\hline & tnf receptor superfamily 5 & tnfrsf5 & GSONMT00012579001 & 155 \\
\hline & tnf receptor superfamily 9 & tnfrsf9 & GSONMT00057532001 & 275 \\
\hline \multirow{3}{*}{$\begin{array}{l}\text { Housekeeping } \\
\text { Genes }\end{array}$} & $60 \mathrm{~S}$ acid ribosomal protein $\mathrm{p} 2$ & $\operatorname{arp}$ & ВT074359 & 192 \\
\hline & actin-beta (aortic smooth muscle) & $a c t b$ & NM_001124235 & 218 \\
\hline & $\begin{array}{c}\text { glyceraldehyde-3-phosphate } \\
\text { dehydrogenase }\end{array}$ & gapdh & NM_001124246 & 287 \\
\hline
\end{tabular}


${ }^{1}$ Automated annotation of transcript GSONMT00035358001, Marancik et al. (26), was changed from "interleukin-1 receptor-like 1-like" to "interleukin-1 receptor 1-like" based on analysis of the omy03 genomic locus that contains three sequence-related, tandem genes (GSONMT00035358001, GSONMT00021943001 and GSONMT00035357001). The primers anneal to exon 9 and exon junction 10/11 in all three genes.

${ }^{2}$ Automated annotation of transcript GSONMT00022297001, Marancik et al. (26), was changed from “interleukin-1 receptor type 2" to "interleukin-1 receptor 1-like" based on analysis of genomic locus from omy03. This gene is actually the 5' region of gene GSONMT00035357001. The primers designed against GSONMT00022297001 also amplify the 5' region belonging to GSONMT00035358001 but have $2 \mathrm{bp}$ mismatch with the 5' region belonging to GSONMT00021943001.

${ }^{3}$ The designations "-a" or "-b" were added to the automated annotation to distinguish between putative paralogues.

${ }^{4}$ Automated annotation of transcript GSONMT00066304001, Marancik et al. (26), was changed from “interleukin-1 receptor type 2-like" to "interleukin-1 receptor type 2 ". 


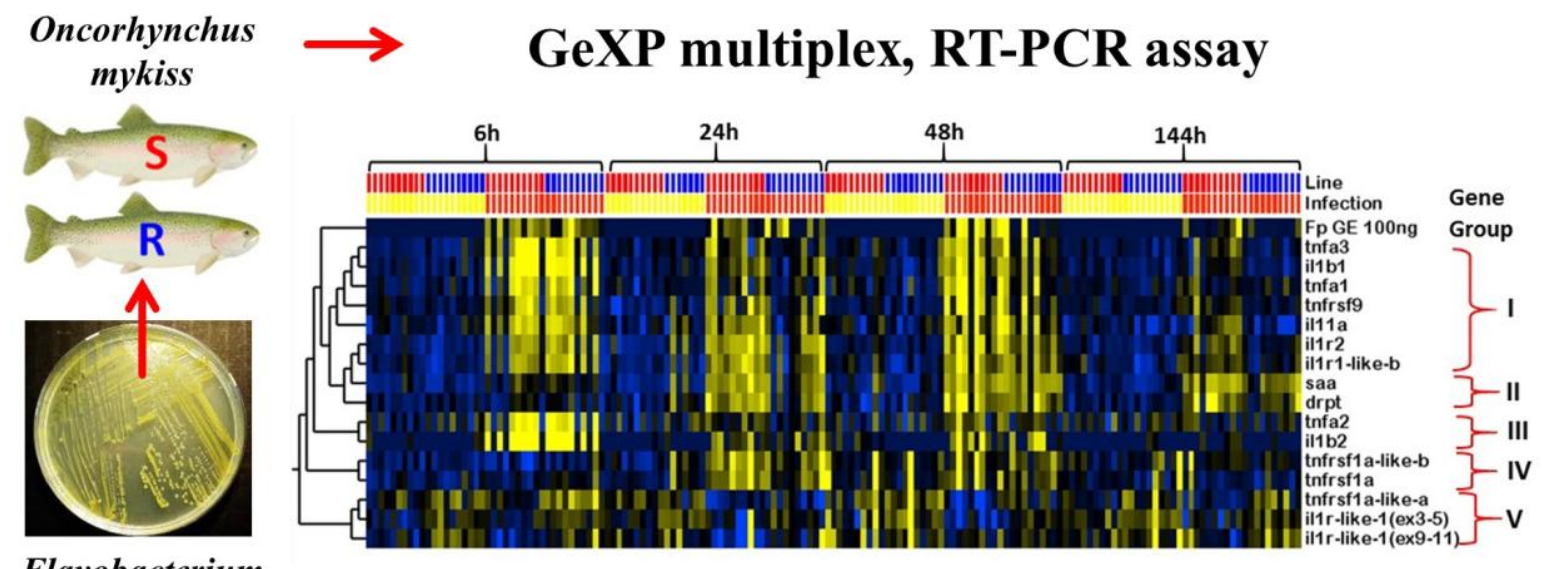

Flavobacterium psychrophilum 